OPEN ACCESS

Edited by:

Sergio Ulgiati,

University of Naples Parthenope, Italy

Reviewed by:

Sarah Elisabeth Cornell,

Stockholm University, Sweden Asmaa Abdelaty Mohamed Ibrahim,

Cairo University, Egypt

Brian Fath,

Towson University, United States

${ }^{*}$ Correspondence:

Gilberto C. Gallopín

ggallopin@gmail.com

Specialty section: This article was submitted to Urban Resource Management, a section of the journal

Frontiers in Sustainable Cities

Received: 29 December 2019

Accepted: 23 September 2020

Published: 29 October 2020

Citation:

Gallopín GC (2020) Cities,

Sustainability, and Complex

Dissipative Systems. A Perspective.

Front. Sustain. Cities 2:523491.

doi: 10.3389/frsc.2020.523491

\section{Cities, Sustainability, and Complex Dissipative Systems. A Perspective}

\author{
Gilberto C. Gallopín * \\ Independent Researcher, Buenos Aires, Argentina
}

This article discusses the role of cities in the Earth System as dissipative systems and presents the significant attributes of urban systems from this perspective. The major facts and problems of cities are briefly recalled emphasizing their complexity, that challenges the standard approaches to urban analysis and planning. In the second section, conceptual aspects of the theory of dissipative structures are briefly introduced, focusing on dynamics and characteristic phenomena. The first two sections feed the third one, examining the reasons that show why a city is a dissipative system. The author thus proceeds to discuss the definitions of the sustainable city, criteria to assess its sustainability, and what is meant by the sustainable development of the city. He also introduces a general systemic framework in which sustainability and sustainable development can be abstracted to its essential elements. It is argued that, because cities are dissipative structures, a city cannot be sustainable if the system is defined as the city itself in isolation from its environment. The increasing challenges to urban sustainability across the world point out to the inadequacy (or at least insufficiency) of the standard approaches to urban sustainability. Those trends, in addition to the emerging global problems, are interpreted in the light of the theory of dissipative structures, suggesting they could indicate the proximity of a bifurcation in the trajectory of the Earth System. An analysis of global scenarios is presented as an illustration of potential planetary trajectories. Finally, the article ends with a set of expected behaviors of the urban systems derived from their condition of dissipative structures, which might contribute to the posing new questions relevant to a research agenda.

Keywords: dissipative structures, sustainability, scenarios, earth system, Fortress world

\section{INTRODUCTION}

It is widely recognized that cities play an important role in the Earth System, and that large urban centers are becoming more and more difficult to manage.

While some information on urban settlements will be presented here, it is not the purpose of this article to make a review of the information on urban settlements, but to present a frame of reference that could help to pose different questions about the dynamics of urban systems, questions of relevance to their management. Most current proposals for management of the cities seek essentially to reach an optimal state (or trajectory) of the system. But the understanding of the dynamics of complex dissipative systems (cities being one example) highlights the danger of such a simplistic approach, and points into other directions.

Nevertheless, some information about the importance of urban settlements within the Earth System is required to provide perspective. Table 1 and Figures 1, 2 show some basic indicators of the global situation. 
Consumption of materials and energy, and the concomitant pollution, are all concentrated in urban areas.

Cities are key contributors to climate change, as urban activities are major sources of greenhouse gas emissions (Solecki and Marcotullio, 2013). Estimates suggest that cities are responsible for 75 percent of global $\mathrm{CO}_{2}$ emissions, with transport and buildings being among the largest contributors (UNEP, 2019). Global urban expansion has caused many ecological and environmental issues, such as losses of biodiversity, increases in carbon emissions, water scarcity,

TABLE 1 | Some basic indicators of the global urban situation.

- More than 4 billion people live in urban areas globally.

- The UN estimates 2007 was the year when, for the first time, more people in the world lived in urban than in rural areas.

- Estimates on urban populations vary - mainly as a result of disagreements on the exact definition of an 'urban area' and what this includes.

- Just under 1-in-3 people in urban areas globally live in a slum household (Figure 1).

- For most of human history, populations lived in very low-density rural settings. Urbanization is a trend unique to the past few centuries (Figure 2)

- By 2050 it's projected that more than two-thirds of the world population will live in urban areas.

- It's projected that close to 7 billion people will live in urban areas in 2050 (Figure 1)

Source: Ritchie, 2018. regional warming, and environmental pollution (Chunyang et al., 2019). Being the places with the highest concentration and quantity of humans, the urban populations are also exposed to receive back the impacts of these environmental changes. Of higher importance, cities are the locus of information generation and exchange and of political, economic, and social decisionmaking reaching to all corners of the planet, all that associated to deep and pervasive physical impacts. And, due to their high population density and connectivity, infectious diseases tend to concentrate within, and disseminate between, urban settlements (the current swift spread of the Covid-19 pandemic being a case in point).

Clearly, the effect of cities upon the Earth System exceed by far their small total spatial extension. Of higher significance is the fact that cities are very complex systems; this complexity is expressed internally (with physical, social, biological, technological, cultural, economic and ethical factors in permanent interaction, determining the dynamics of the cities and the quality of life of their inhabitants). But is also evident in the multiple interactions defining one or more "suprasystems" or networks of interconnected cities along the planet. As an example, Figure 3 maps the system of main submarine cables providing internet connectivity between continents. The full system of connections, including also the terrestrial links, is too complex to depict in a figure in this paper, but it can be appreciated online, for instance, at https://www.todaybyt.com/ 2019/10/internet-map.html. Another illustrative rendering of

Urbanization over the past 500 years, 1500 to 2016

Share of the total population living in urban areas.

$100 \%$

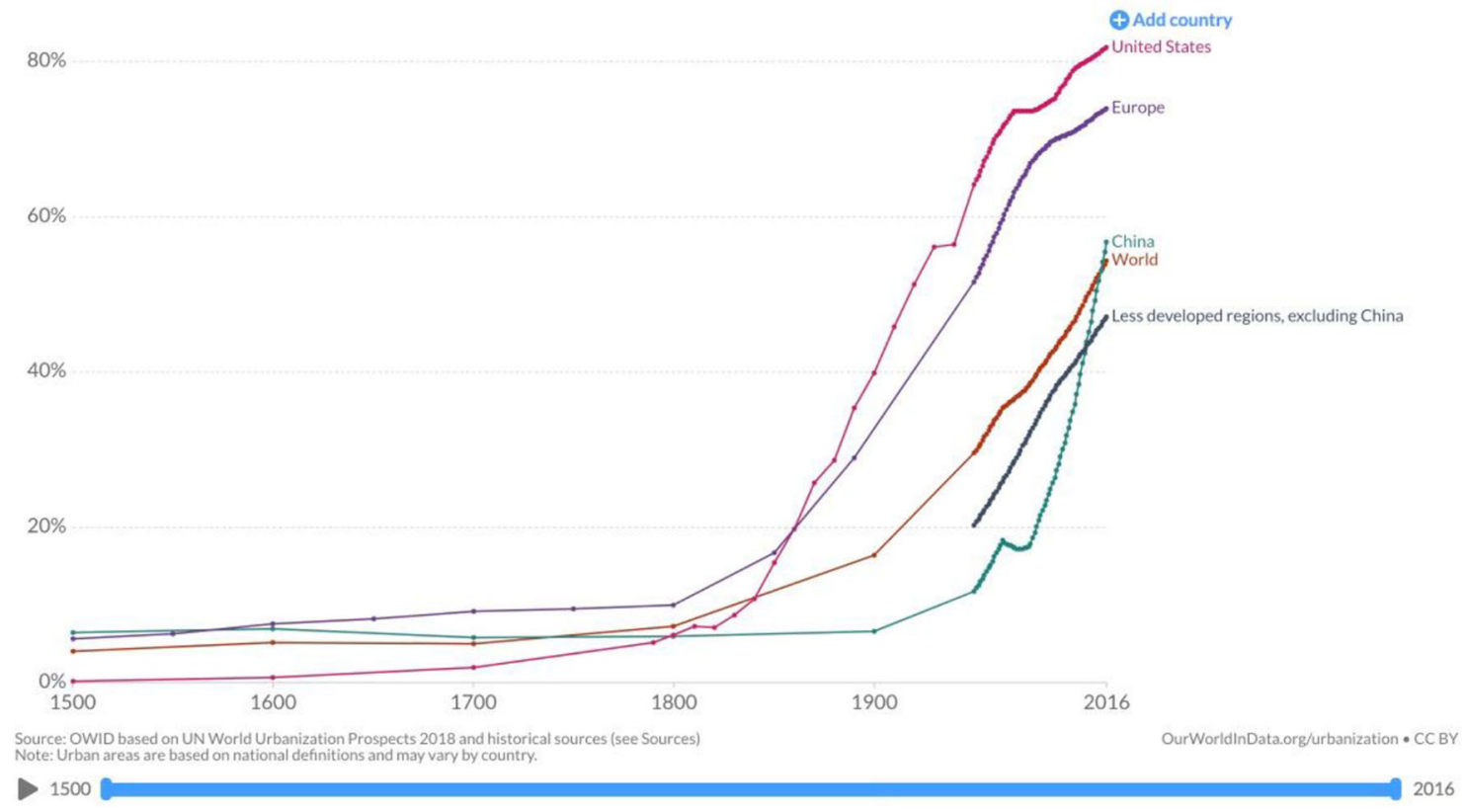

FIGURE 1 | Urbanization over the past 500 years. Source: https://ourworldindata.org/grapher/urbanization-last-500-years?time=1500..\&country=OWID_ WRLIsimCHNIsimUSAlsimEuropelsimLess\%20developed\%20regions\%2C\%20excluding\%20China. 
Urban and rural population projected to 2050, World, 1500 to 2050 Total urban and rural population, given as estimates to 2016, and UN projections to 2050. Projections are based on the UN World Urbanization Prospects and its median fertility scenario

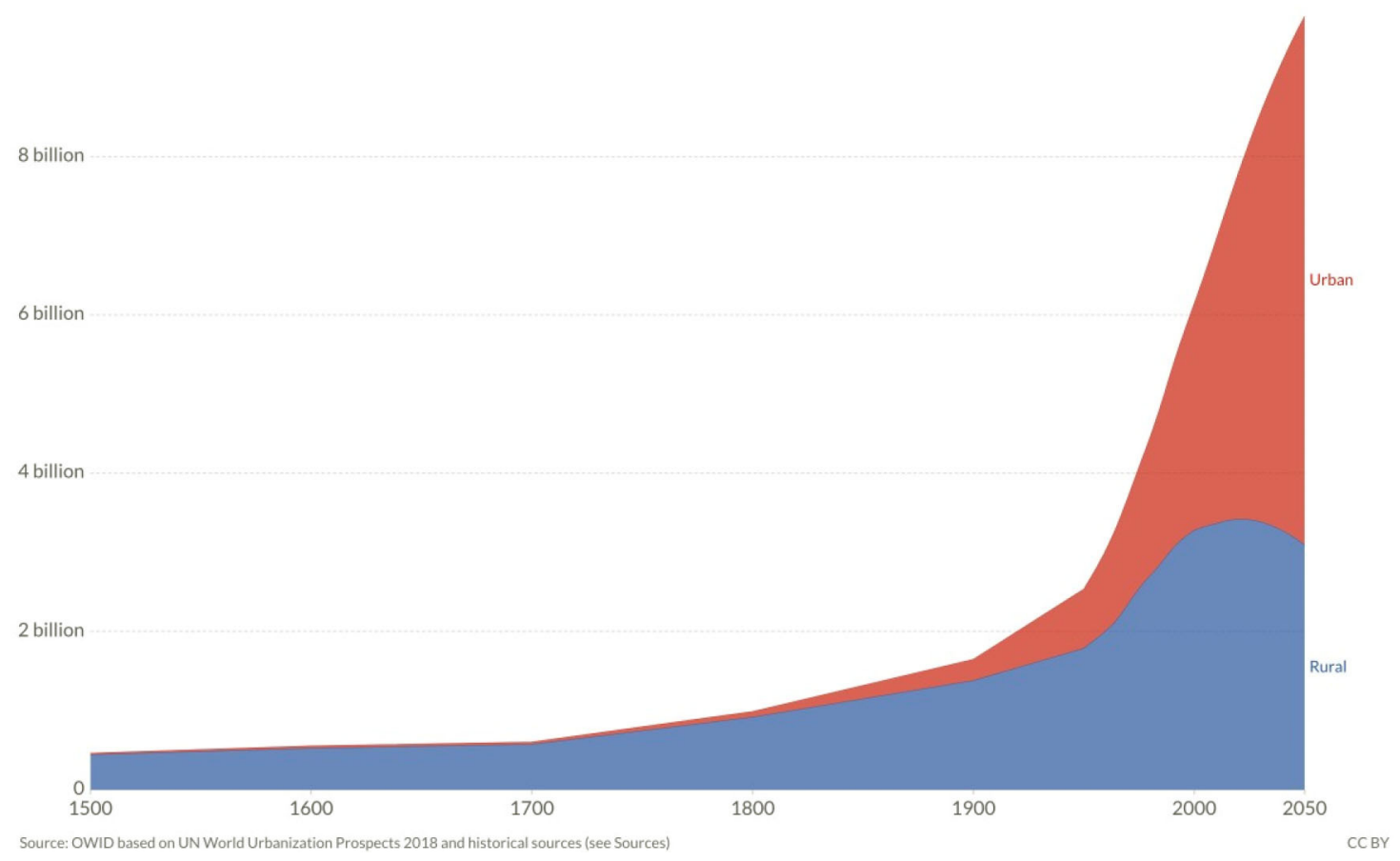

FIGURE 2 | Urban and rural population size. Source: https://ourworldindata.org/grapher/urban-and-rural-population-2050.

the interconnections is the global air traffic network, available online at http://www.martingrandjean.ch/connected-world-airtraffic-network. And the complexity is fast increasing.

Because of their complexity, connectedness, and speed of change, urban settlements have a dynamics that is not amenable to the classical thinking based on linear cause-and-effect chains. The failures of the standard approach of urbanization are explicitly recognized by the UN Habitat, the United Nations Human Settlements Programme (see Table 2).

Complexity is usually characterized in terms of nonlinearity, interconnectedness, emergent properties, and number of components. Obviously, cities share all of these traits, as well as do many other systems, both existing in the real world and in formal models and structures. But the question explored here: are there general systemic properties of urban systems that could lead to new insights for understanding and managing?

\section{DISSIPATIVE STRUCTURES}

The theory of dissipative structures developed essentially by the Chemistry Nobel prize winner Ilya Prigogine and his collaborators (Nicolis and Prigogine, 1977; Prigogine and Stengers, 1979) shows that open, self- organizing systems maintain their structural order by keeping their internal state far from thermodynamic equilibrium, through active exchanges with their environment. The maintenance of the structural, nonequilibrium, low entropy, order involves continuous entropy production, which is exported to the outside the system (its environment). In other words, dissipative structures import negentropy ("negative entropy") and export entropy to maintain internal order. The stability of dissipative structures is different in kind from stability in steady states. It is not a result of a low production of entropy, but instead, of their ability to transfer to their environment great quantities of entropy due to their greater complexity (for example under the guise of heat or degraded products). Consequently. when a system organized through dissipative structures does appear, its environment tends to become growingly disorganized (IESC, 2004, article 3232).

This theory deals with the processes of self-organization in systems fulfilling some basic conditions: openness toward their environment, a global system state far from thermodynamic equilibrium, and hypercycles, or autocatalytic non-linear selfreinforcement of certain steps in their internal processes (the hypercycles are sets of reactions, where some elements catalyze the self-replication of other elements in sequence and where the latter catalyzes the first). Hypercycles occur in chemical and biological (Eigen, 1971) but also on social systems (Kamiński and Koloch, 2013, Powell and Padgett, 2012).

Some physico-chemical, all biological and all social systems fulfill these conditions and can therefore be rightfully considered as dissipative systems.

Those dissipative structures are in principle stable as long as the exchanges with the environment are maintained and as long as the continuously occurring fluctuations (or perturbations) 


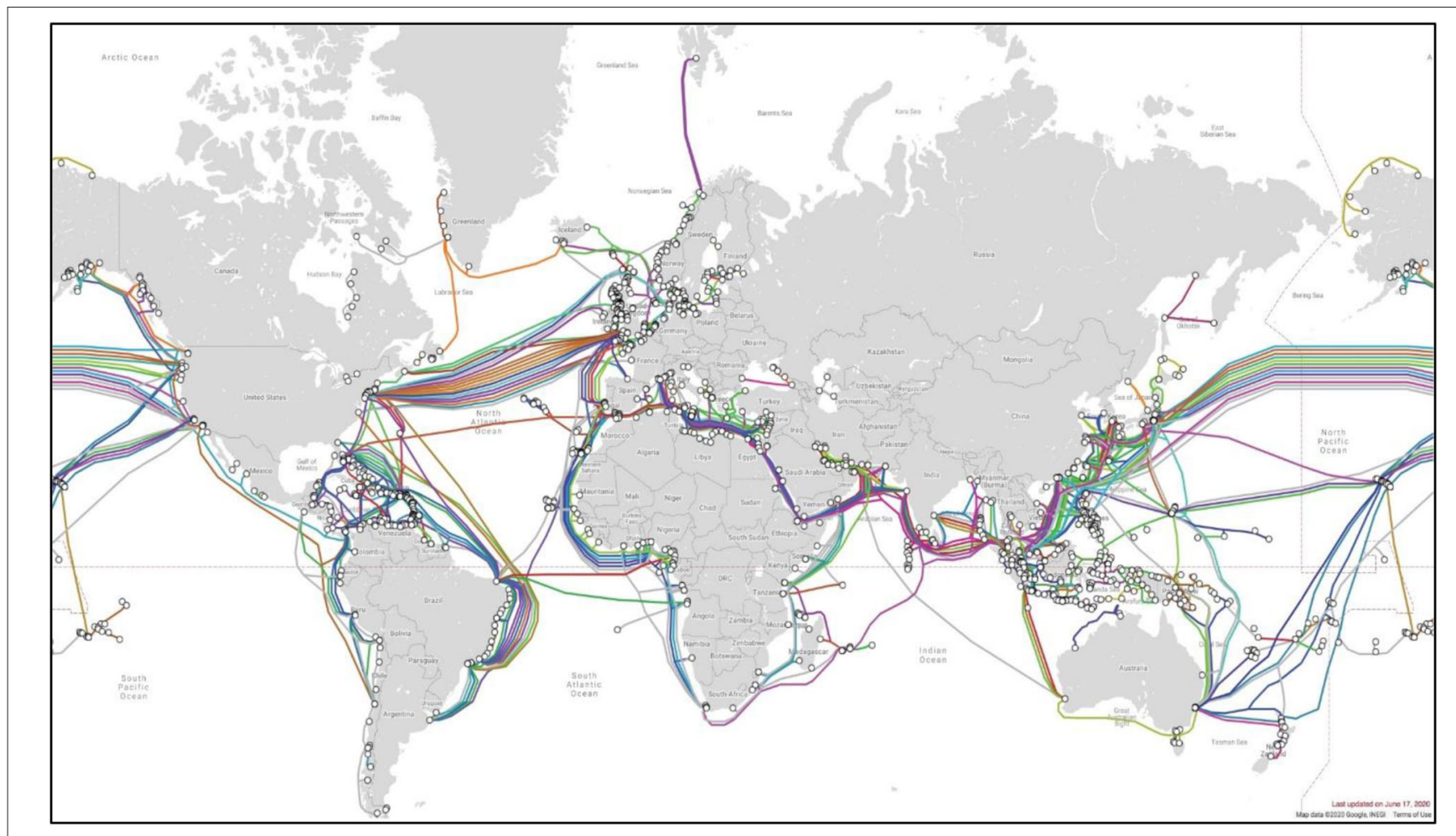

FIGURE 3 | Network of intercontinental optical internet cables. Source: https://www.submarinecablemap.com/.

TABLE 2 | Basic points about urbanization in the world.

\section{QUICK FACTS}

1 Urban areas around the world are facing enormous challenges and changes than they did 20 years ago.

2 Cities are operating in economic, social, and cultural ecologies that are radically different from the outmoded urban model of the Twenty century.

3 Persistent urban issues over the last 20 years include urban growth, changes in family patterns, growing number of urban residents living in slums and informal settlements, and the challenge of providing urban services.

4 Connected to these persistent urban issues are newer trends in the urban governance and finance: emerging urban issues include climate change, exclusion and rising inequality, rising insecurity and upsurge in international migration.

\section{POLICY POINTS}

1 When well-managed, urbanization fosters social and economic advancement and improved quality of life for all.

2 The current model of urbanization is unsustainable in many respects.

3 Many cities all over the world are grossly unprepared for the challenges associated with urbanization.

4 A new agenda is required to effectively address these challenges and take advantage of the opportunities offered by urbanization.

5 The new urban agenda should promote cities and human settlements that are environmentally sustainable, resilient, socially inclusive, safe and violence-free and economically productive.

Source: UN-Habitat, 2016, p.1.

are absorbed within the framework of the given dynamic regime. However, any structure of a non-equilibrium system may be driven beyond a threshold into a new regime when the fluctuations exceed a critical size. This corresponds to a qualitative change in the dynamic existence of the system, a bifurcation of its line of evolution. An important point is that such fluctuations may be originated not only from the outside of the system, but also, they may be internal fluctuations that become self-amplified through positive feedback. In either case, after passing through phases of instability and high entropy, the system may evolve to a different stable regime with a new characteristic structure.

The probability that a fluctuation spreads and attains a macroscopic amplitude and range depends on the competition between the amplifying and damping forces within the system. The size and complexity of the system are important factors for the formation of new dissipative structures; a dissipative structure comes into being when a specific critical size can be realized. A system that is too small will always be dominated by the boundary effects. Besides size, the penetration of perturbations and the formation of new dissipative structures depend on sufficiently dense packing or cohesion of the fluctuating elements or subsystems on the one hand, and on flexible, not too strong and rigid coupling with the rest of the subsystems on the other.

When the state of the system is away from the transition threshold, it may remain at a dynamic steady state far from thermodynamic equilibrium, or change gradually over time, and a deterministic description can be applied; however, near the threshold, stochastic elements become essential in determining the new structural regime. The path which the evolution of the system will then take cannot be predicted, there being 


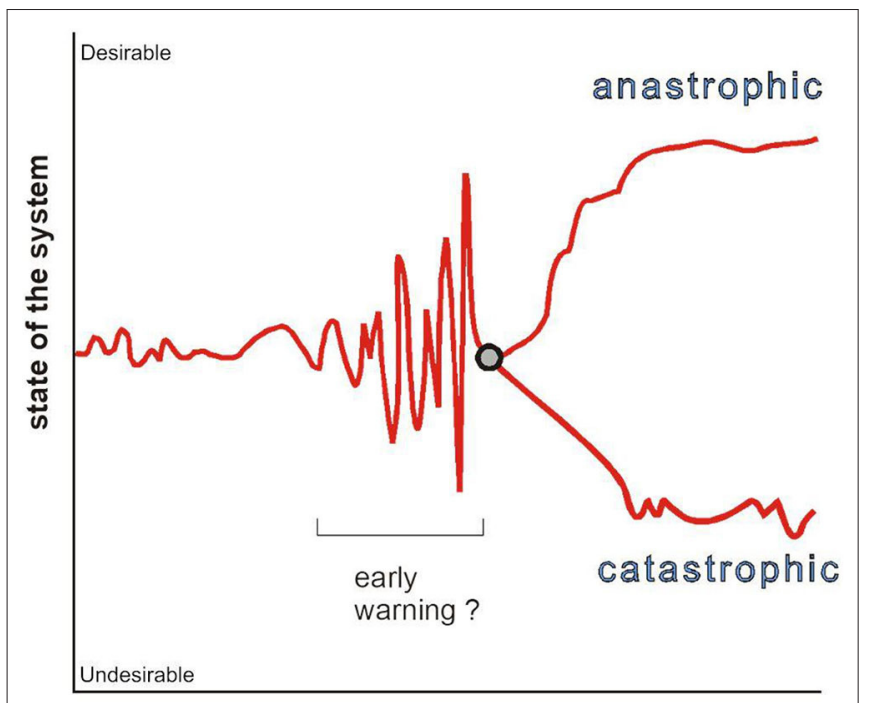

time

FIGURE 4 | Catastrophic and anastrophic trajectories in a dissipative structure. Source: own elaboration.

always more than one emerging, qualitatively different, structure available. This transition to a new regime, depending on the properties of the system and of the perturbation, may be relatively "smooth" or may represent an abrupt jump to a new domain

As depicted in Figure 4, those transformations can be catastrophic (sudden drops to an lower, simpler, organization) or anastrophic (sudden moves toward new and higher organization levels -Gallopín, 1994- better able to deal with the exchanges between the system and its environment); the catastrophic and anastrophic transformations (not mere changes in state) can be viewed and undesirable and desirable, respectively, but this represents value judgements that can only come from the social subsystem of the considered socio-ecological system.

The characteristics of those transformations are inherently unpredictable, but structural transformations are often preannounced by increases in entropy and turbulence of key system variables; this can sometimes be used to anticipate critical transitions of the system (Scheffer et al., 2012). These periods of turbulence not only serve as an early warning, but as a time when small actions can self-amplify and change the future trajectory.

\section{CITIES ARE DISSIPATIVE SYSTEMS}

A city is, in a sense, a temporospatial "anomaly," a local concentration of energy, materials, information, and human beings in a generally smoother landscape of geographical and temporal variation.

A city fulfills the basic conditions of a dissipative structure. This has been recognized by a number of authors. Peter Allen, from the Prigogine school, used this approach to model urban evolution in a number of cities (Allen, 1997). Other authors, such as Alberti (1996) and Dyke, 1988 applied the approach of dissipative systems to urban systems. The focus of the use of the Prigogine theory in the present paper is on the strategic implications of the potential qualitative behavior that can be expected from the interpretation of cities as dissipative structures, rather than modeling or proposing theoretical frameworks.

A city maintains itself thanks to the permanent flow of materials, energy, and information, which keeps it away from its thermodynamic equilibrium value. A big city is a huge dissipative system (sensu Prigogine) that consumes energy, information and materials, and generates "things" that can hardly be produced outside the city. This activity is what it is usually characterized as "urban metabolism." And the state of the city may or may not be a dynamic steady state, but is certainly far away from its thermodynamic equilibrium point.

Cities absorb flows of high-quality energy from the external environment and emit heat, wastes and pollutants; their internal entropy decreases by self-organization in the form of structures, information, social patterns and economy (Tiezzi et al., 2008).

The basic characteristics of the city as a dissipative system are:

- It is an open system, with a permanent exchange of energy, materials and information with its environment, essential for its metabolism and survival.

- It has a dense packing that favors a high concentration of "reactants" (interacting entities) and a high number and frequency of human-human, human-things and thingsthings interactions.

- It contains hypercycles or autocatalytic cycles, within both the physical and social realms.

\section{SUSTAINABLE CITIES}

A city typically consumes much more energy and materials than it produces, as can be (and have been) measured for example through the ecological footprint (Wackernagel and Rees, 1996), life-cycle assessment (Jensen et al., 1998), ecological rucksack (Schmidt-Bleek, 1994), and urban metabolism (Kennedy et al., 2007). This is to be expected from its condition as a dissipative structure, exporting entropy to its (human and non-human) environment. Thus, in this sense, and from an extreme deep ecology perspective, cities might be viewed as parasites within the Earth System.

On the other hand, cities produce much more of other "things" than what they consume. Thus, from another perspective, cities can be regarded as "brains," regulators, the places of opportunity and better life. Some of those products of the city are culture, information and knowledge, living conditions (employment, education, satisfaction of needs, social capital, economic wealth, governance, etc.). Of course, they also produce wastes, pollution, and alterations of the external habitats, as already mentioned.

Given that cities, as dissipative structures, maintain or increase their level of organization and complexity by exporting entropy, thus disorganizing their environment, the questions that arise are: What is a sustainable city? What criteria allow us to say that a city is or is not sustainable? What does the sustainable development of a city mean? Can a city be sustainable? 
There is not a unanimous concept of "sustainable city" in the literature; it has been given different meanings, among these, recyclable city, compact city, green city, just city, and participatory city. The terms smart city and green city have also been associated with sustainability (Hamman, 2017). According to the same author, other words that have been associated with sustainable urban development ${ }^{1}$, such as degrowth, resilience, sustainable transformation and transition.

In recent years, the concept of smart cities has been gaining importance. Two visions can be distinguished: the one that focuses on the role of Information and Communications Technology (ICT); and that which is extended to notions related to sustainable economic growth, quality of life, participatory governance and emissions reduction (Alderete, 2019).

Could a medium to large city become really self-sufficient, completely generating or recycling its needed resources? Probably not, with the possible exception of small settlements with inhabitants living simple lives. Even the ambitious plan for Barcelona to become an energy self-sufficient city (BARCELONA Towards energy self-sufficiency by 2050) recognizes that the city will need to supplement its energy sources by cooperating with the surrounding rural communities. And energy is only one of the external resources needed to maintain urban metabolism.

Important insights have been obtained from artificial closed ecological systems including human beings that do not rely on matter exchange with the outside of the system (i.e., the famous Biosphere two experiment ${ }^{2}$ ). It should be noted that the system was not closed to energy exchanges. The possibility of closed settlements including humans is being considered today for the colonization of other planets, but the fact that even highly planned, well-financed and technoscience-informed experiments in semi-closed system living such as Biosphere are not viable for the expected lapse of time puts their feasibility in doubt (unless, of course, the system is not really closed to matter but is subsidized and regulated from the outside).

Clearly, urban sustainability cannot be defined in terms of closedness with regards to its external environment (perfect recycling and self-sufficiency), although some proponents of smart cities as the panacea seem to suggest this. A city, as dissipative system, requires exchanges with its environment.

As mentioned above, sustainability, like sustainable development, has been defined in many different ways. However, using a general systemic framework, sustainability can be abstracted to its essential elements as follows: (Gallopín, 2003; Gallopín et al., 2014):

$$
\begin{aligned}
V\left(S_{t+1}\right) & \cong V\left(S_{t}\right) \\
\text { for } t_{0} & \leq t \leq t_{f}
\end{aligned}
$$

Where $V$ is a valuation function of the state or condition of the urban system $(S)$. In words, the equation says that a city is sustainable (within the interval between the initial time $\left(\mathrm{t}_{0}\right)$

\footnotetext{
${ }^{1}$ Note that sustainability and sustainable development are fundamentally different concepts, the first implying permanence and the second change, improvement (Gallopín, 2003; Gallopín et al., 2014).

${ }^{2}$ See https://en.wikipedia.org/wiki/Biosphere_2\#Current_research for a synthesis.
}

and the final time $\left(\mathrm{t}_{\mathrm{f}}\right)$ considered), if the net "value" of the city remains approximately the same over time $(\mathrm{t})$. Note that this formulation applies to $V$ and does not necessarily imply that the system $S$ remains in a stationary or constant state. Indeed, all dissipative systems maintain their identity through a dynamics of permanent adjustments, adaptations, and selforganizations. What is more, change and adaptation can be considered as constitutive properties of sustainability, since, ultimately, it is a matter of maintaining the co-evolutionary capacity of social and natural systems to deal with fluctuations and adapt to transformations.

Different from sustainability, the formal definition of sustainable development is (Gallopín et al., 2014):

$$
\begin{aligned}
V\left(S_{t+1}\right) & >V\left(S_{t}\right) \\
\text { for } t_{0} & \leq t \leq t_{f}
\end{aligned}
$$

Which means that the value $V$ of the city grows sustainably. Development is used here in his original conception, of an essentially qualitative unfolding of potentialities, not to be confused with quantitative increase (and specially not with indefinite material growth). In the dissipative structures' framework, sustainable development can be seen as progress to higher levels of organization, while sustainability is more about permanence around a steady state or condition.

The systemic formulation allows a better understanding of the plethora of definitions of sustainability. Part of the confusion arises because different definitions are based on different implicit valuation functions $V$. For instance: the monetary value of the products generated by the city, the esthetical value of the urban habitat, the quality of life of its citizens, the efficiency in the use of resources, a combination of these, and so on. For cities, an appropriate valuation function should be plural, combining material and non-material aspects.

Another source of discrepancies lies in the implied conception of the subject (the system $S$ ) of sustainability: the "inner" sustainability of the city? (its ability to maintain habitability and living conditions acceptable to its inhabitants), the "outer" sustainability of the city? (its ability to maintain the flow of value delivered to the supra-city level and to minimize consumption of external resources and production of wastes), or both of them (as it would be the case if the whole urban socio-ecological system including its external interactions is taken as the unit of analysis?

No wonder the definitions of sustainability go all over the place. The term "urban sustainability" is underdefined unless the valuation criteria used and the urban system addressed are made explicit. And this varies according to who is defining sustainability (his/her goals and power to impose them, the election of the value function, and the definition of the subject of sustainability.

And finally, regarding the question of whether a city can ever be sustainable, the answer would be no, if defining only the city as the system $S$. For a given valuation function $V$, according to the dissipative structures framework, a city by itself can never be sustainable during a long time; it requires an environment with which it exchanges energy and matter, importing negentropy and exporting entropy. 
As a consequence, the unit of analysis for the study of the dynamics and the sustainability of cities and the setting of urban policies should be broader than the city itself; it becomes necessary to include the environment within which the city interacting to maintain its internal structure, in the definition of the system $S$.

\section{CITIES: THE DARKER SIDE}

According to the UN-Habitat (2016) (see Table 2 in this paper), urban areas around the world are facing enormous challenges and changes. And the Organization concludes that "the current model of urbanization is unsustainable in many respects," and that "many cities all over the world are grossly unprepared for the challenges associated with urbanization."

In many cities in both rich and poor countries, digitalization is penetrating rapidly, often promising big improvements in the quality of life to those that have access to them. But when ICT is deployed unevenly, it creates a digital divide, which exacerbates inequality, leading to a situation characterized by well-connected affluent neighborhoods coexisting with under-serviced residents in low-income neighborhoods (UN-Habitat, 2016).

Around, within and in the interstices of the formal cities, there exist an informal city, self-constructed, and where legal rules do not exist or do not apply. This is long known fact, but it has acquired massive importance in the context of the accelerated urbanization dynamics illustrated in Figure 2. According to the World Bank (2015) nearly one in every three urban residents in the developing world-or a total of one billion people-live in slums (see also Table 1). Still, cities are powerful attractors for people, both from the national rural areas and from abroad, including refugees and other expatriates.

Urban settlements are the places where power and population are concentrated, and where inequalities are most clearly visible, sometimes no farther than a block away. And where discontent and uprisings are becoming a response to frustrated expectations, lack of hope and indignation at inequities in many cities of both the industrialize and developing world. Also, in many instances, where people are hostile to people, particularly people living in the slums or arriving as refugees.

All over the world, in countries such as Chile, France, Lebanon, Haiti, Peru, Egypt, Bolivia, Iraq, Ecuador, the Chinese special administrative region of Hong Kong, protests are erupting variously focused on issues such as corruption, the cost of living, political freedom, income inequality, and inaction regarding climate change. Some of them are nation-wide uprisings, some originate in the rural areas, but all express themselves most strongly in the cities.

On the one hand, these phenomena clearly signal that the standard approaches to urban sustainability are not working, that an approximation that centers on the fundamental processes determining the dynamics and adaptive capacities of urban systems is urgently required.

One could hypothesize that the above "fluctuations" or "perturbations" are not only the symptoms of dissatisfaction with the current state of affairs, but also indicators of increasing turbulence that signal the proximity of a threshold leading to a bifurcation toward a new regime (an anastrophic or catastrophic reorganization). Certainly, there are many independent indications that the current trajectory of the Earth System is not sustainable; examples abound in both the social and the physical realms, such as (a) the unprecedented increase in inequality within and between countries (Alvaredo, 2017), and (b) the magnitude (IPCC, 2014) and potential abruptness (Drijfhout et al., 2015) of climate change. To these the current Covid-19 pandemics and its economic and cultural consequences should be added. These are mega fluctuations in the Earth System that will have a huge impact also on the urban systems.

The fact that resulting organization after a systemic change is not predictable in dissipative structures, points, in addition to the many uncertainties that are already unfolding, to the urgent need to develop novel planning and management approaches that accept, and navigate with, uncertainty.

Whether or not these phenomena are early warning signals of systemic reconfiguration can only be resolved through further observations and scientific research (or by experience, if the bifurcation happens fast enough), but the conjecture is in line with the essential dynamics of the Earth System as a dissipative structure, and with the examination of recent trends within a global scenarios framework (Gallopín, 2018).

\section{AN EXERCISE IN SCENARIOS}

An hypothetical visualization of what kind of new configurations could arise from the reorganization of the Earth System is the evolution of the global scenarios created by the Global Scenario Group (GSG), available online at https://www.gsg.org/gsgintro.html.

The scenarios were generated 20 years ago by the GSG, an international, interdisciplinary and intercultural group, recognizing that, at any time, there is multiplicity of possible futures, and that the business as usual trajectory could not be sustained much longer. Three alternative basic classes of scenarios were identified (Gallopín et al., 1997; Raskin et al., 1998, 2002):

1. Conventional Worlds, deriving without sharp deviations from present, having the variants Market Forces and Policy Reform.

2. Barbarization, incorporating the possibility of deterioration in civilization, as problems overwhelm the coping capacity of both markets and policies, with the variants Fortress World and Breakdown.

3. Great Transitions, contemplating visionary solutions to the sustainability challenge, including fundamental changes in the prevailing values as well as novel socio-economic arrangements, with the variants Eco-communalism and New Sustainability Paradigm. In this conception, the alternative scenarios began to bifurcate (exhibit systemic reorganizations) following a period of increased turbulence (Figure 5), culminating in different shapes of the future ca. the year 2100 (Figure 6). 


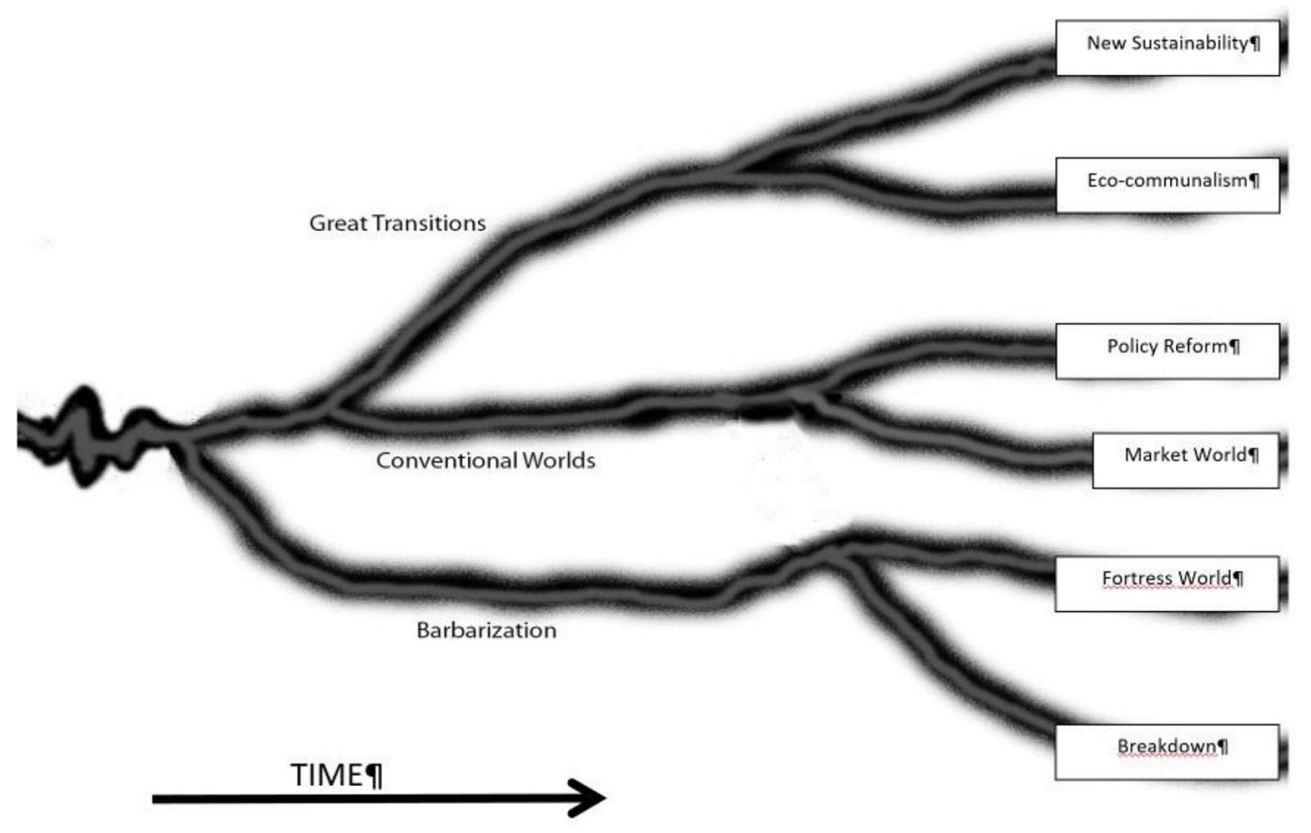

FIGURE 5 | The scenarios of the GSG. The position of the scenarios in the figure does not imply any particular ordering; the figure is only a symbolization of bifurcation trajectories from an initial condition. Source: author's elaboration.
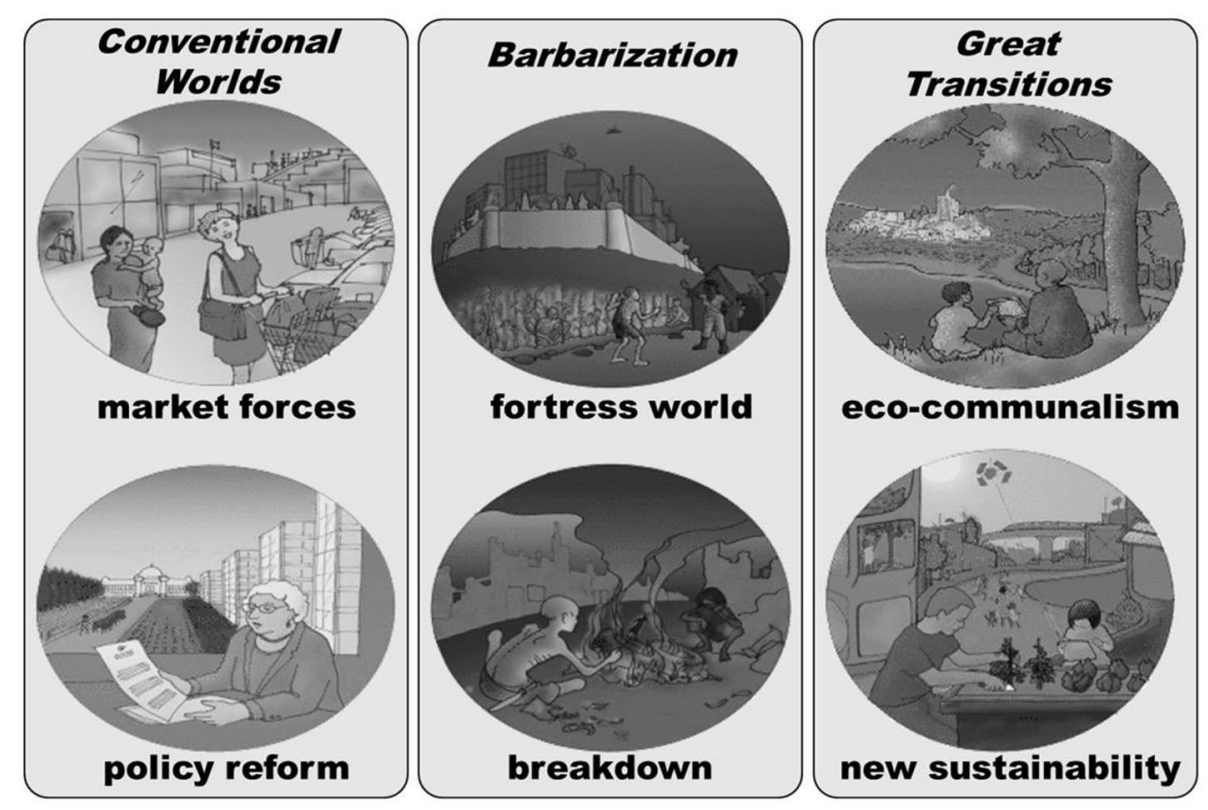

FIGURE 6 | The classes of images of the future under the GSG scenarios. Source: Gallopín et al. (1997).

The consideration of the new trends (from the last two decades) suggests that, although there is a mix of good news and bad news, collectively they are most compatible with the barbarization scenarios, mainly the Fortress World. Glimpses of this world can already be perceived in a number of countries, with indicators such as increasing inequality, growing number of refugees, xenophobia, impacts of climate change, international terrorism (Gallopín, 2018).

In the Fortress World scenario, the powerful join forces to protect their privileged situation by entrenching themselves into "bubbles of wealth" excluding the majority of the world population from accessing resources considered strategic, and 
controlling the per capita consumption and demographic growth of the disfranchised population. This is very similar to what is possible to see in many cities of the world, where the dispossessed, excluded and refugees are confined to the margins and the affluent create enclosures (virtual and physical) for preserving their comfort and security. And the gap is widening rather than disappearing. This is clearly an unstable state of affairs, but one that could last for decades. If the valuation function $V$ in the systemic definition of sustainability is the aggregate quality of life of people, rather than the rate of production of wealth is used, most cities are already shown to be unsustainable.

It is in the cities where these dynamics are manifested more rapidly and vividly, and it is from the cities of the world where the initiatives that could change course or reinforce the likelihood of falling into barbarization scenarios will arise. And the window of opportunity to change direction is rapidly closing, as the current course is already cracking, with climate change evolving faster than anticipated, and social dissatisfaction in the increase. But governments and institutions seem to be too slow to act on time, as shown by the pitifully insufficient official reaction to the global climate change problematique. The theory of dissipative structures and other evidences tell us that in times of turbulence and systemic reconfiguration small actions can self-amplify and transform the future. There lies hope?

\section{CONCLUDING REMARKS}

Analyzing the cities as dissipative structures has the consequence of providing the following general expectations:

- That, because in order to maintain their complex order far from equilibrium, cities export entropy (disorder) to their environment, it becomes necessary for both analytical and management purposes, to broaden the unit of analysis, from the city itself to the wider socio-ecological system composed by the city and its environment.

- That the city may suffer relatively abrupt ${ }^{3}$ structural transformations as the tensions in the city or between it and its environment intensify, alternating with periods of relative structural stability (although they may be of high functional dynamism). They refer to continuously occurring external or internal perturbations potentially driving the system beyond

\footnotetext{
${ }^{3}$ Abruptness is relative to the characteristic time scale of the system. For a city, it could mean a change that takes place in years to a few decades.
}

\section{REFERENCES}

Alberti, M. (1996). Measuring urban sustainability. Environ. Impact Assess. Rev. 16, 381-424. doi: 10.1016/S0195-9255(96) 00083-2

Alderete, M. V. (2019). Qué factores influyen en la construcción de ciudades inteligentes? Un modelo multinivel con datos a nivel ciudades y países. Revista CTS, 14 71-89.

Allen, P. M. (1997). Cities and Regions as Self-Organizing Systems Models of Complexity. London New York, NY: Taylor \& Francis.

Alvaredo, F. (2017). World Inequality Report 2018. WID Lab. Available online at: https://wir2018.wid.world/files/download/wir2018-full-report-english.pdf a threshold into a new regime. Collapse of the inner city, phantom towns (and other forms of urban decay) or rapid city renewal and development might be examples.

- That these transformations can be catastrophic or anastrophic.

- That they could be triggered by external events but also by internal fluctuations that become amplified.

- That the characteristics of these transformations are inherently unpredictable.

- That, between structural transformations, the city could stabilize in a new steady state or a new relatively continuous and smooth trajectory.

- That there will be a plurality of stationary states or alternative evolutionary trajectories.

- That structural transformations will be preannounced by increases in entropy and turbulence in key city variables.

- That small actions and nudging could more effective, during the phase of turbulence preceding system restructuration, than massive actions during the stable phases.

If we view cities as dissipative systems, we can characterize some rapid urban changes and reconfigurations not just in terms of bad catastrophes, but also as desirable anastrophesreconfigurations where functioning processes are maintained or improved. As open systems, cities have both material and sociocultural exchanges with their environment/context. Bringing these elements of dynamic change and exchange together can result in a new perspective on sustainable development and urban sustainability.

These considerations could contribute to define a new research agenda on the sustainability and sustainable development of cities, leading to new urban planning and management styles, diving beyond the standard resilience studies into the deeper structural dynamics of the urban systems.

\section{AUTHOR CONTRIBUTIONS}

The author confirms being the sole contributor of this work and has approved it for publication.

\section{ACKNOWLEDGMENTS}

The author wishes to thank the reviewers, some of which provided very constructive and useful comments on the first submitted version of this article.

\footnotetext{
BARCELONA Towards energy self-sufficiency by 2050. Available online at: https:/energy-cities.eu/wp-content/ uploads/2019/01/Barcelona_100_RES.pdf (accessed December 24, 2019)

Chunyang, H., Zhifeng, L., Siyuan, G., Qiaofeng, Z., Jinshui, Z., Linlin, X. (2019). Detecting global urban expansion over the last three decades using a fully convolutional network. Environ. Res. Lett. 14:034008. doi: $10.1088 / 1748-9326 /$ aaf 936

Drijfhout, S., Bathiany, A., Beaulieu, C., Brovkin, V., Claussen, M., Huntingford, C., et al. (2015). Catalogue of abrupt shifts in intergovernmental panel on climate change climate models. Proc. Natl. Acad. Sci. U.S.A. 112, E5777-E5786. doi: $10.1073 /$ pnas. 1511451112
} 
Dyke, C. (1988). The Evolutionary Dynamics of Complex Systems: A Study in Biosocial Complexity. Oxford: Oxford University Press.

Eigen, M. (1971). Self-organization of matter and the evolution of biological macromolecules. Die Naturwissenschaften 58, 465-523. doi: 10.1007/BF00623322

Gallopín, G. (2018). Back to the future. Energy Policy 123, 318-324. doi: 10.1016/j.enpol.2018.08.060

Gallopín, G., Jiménez Herrero, L. M., and Rocuts, A. (2014). Conceptual frameworks and visual interpretations of sustainability. Int. J. Sustain. Dev. 17, 298-326. doi: 10.1504/IJSD.2014.064183

Gallopín, G. C. (1994) Sustainable Development. A Systems Approach. Winnipeg, MB: International Institute for Sustainable Development.

Gallopín, G. C. (2003). "A systems approach to sustainability and sustainable development”. Serie medio ambiente y desarrollo No. 64, Sustainable Development and Human Settlements Division, Economic Commission for Latin America and the Caribbean, Santiago, Chile.

Gallopín, G. C., Hammond, A., Raskin, P., and Swart, R. (1997). Branch Points: Global Scenarios and Human Choice. Stockholm: Stockholm Environment Institute.

Hamman, P. (2017). Definitions and Redefinitions of Urban Sustainability: A Bibliometric Approach. Environmement Urbain? Urban Environment. Available online at: https://journals.openedition.org/eue/1540

IESC (2004). IESC: International Encyclopedia of Systems and Cybernetics ed. C. Francois Saur, Munich, 2nd Ed.

IPCC (2014). Climate Change 2014. Synthesis Report. IPCC: Geneva. Available online at: https://ar5-syr.ipcc.ch/index.php

Jensen, A., Elkington, J., Kim, C., Hoffmann, L., Møller, B. T., Anders, S., et al. (1998). Life Cycle Assessment (LCA) - A Guide to Approaches, Experiences and Information Sources Environmental Issues Series No. 6. European Environment Agency.

Kamiński, B., and Koloch, G. (2013). Advances in Social Simulation: Proceedings of the 9th Conference of the European Social Simulation Association. New York, NY: Springer. doi: 10.1007/978-3-642-39829-2

Kennedy, C., Cuddihy, J., and Engel-Yan, J. (2007). The changing metabolism of cities. J. Ind. Ecol. 11, 43-59. doi: 10.1162/jie.2007.1107

Nicolis, G., and Prigogine, I. (1977). Self-organization in Non-equilibrium Systems: From Dissipative Structures to Order Through Fluctuation. New York, NY: John Willey \& Sons.

Powell, W., and Padgett, J. (2012). The Emergence of Organizations and Markets. New York, NY: Princeton University Press.

Prigogine, I., Stengers, I. (1979). La Nouvelle Alliance. Métamorphose de la Science: Paris: Gallimard.
Raskin, P., Banuri, T., Gallopín, G. C., Gutman, P., Hammond, A., Kates, R., et al. (2002). Great Transition. The Promise and Lure of the Times Ahead. Stockholm: Stockholm Environment Institute.

Raskin, P., Gallopín, G. C., Gutman, P., Hammond, A., and Swart, R. (1998). Bending the Curve: Toward Global Sustainability. Stockholm: Stockholm Environment Institute.

Ritchie, H. (2018). - "Urbanization". Published online at OurWorldInData.org. Retrieved from: https://ourworldindata.org/urbanization

Scheffer, M., Carpenter, S. R., Lenton, T. M., Bascompte, J., Brock, W., Dakos, V., et al. (2012). Anticipating critical transitions. Science 338, 344-8. doi: $10.1126 /$ science. 1225244

Schmidt-Bleek, F. (1994). Wieviel Umwelt Braucht der Mensch. Berlin: Birkh“auser. doi: 10.1007/978-3-0348-5650-8

Solecki, W., Marcotullio, P. J. (2013). Climate change and urban biodiversity vulnerability. In: T. Elmqvist, et al.editors. Urbanization, Biodiversity and Ecosystem Services: Challenges and Opportunities. Dordrecht: Springer. doi: 10.1007/978-94-007-7088-1_25

Tiezzi, E. B. P., Pulselli. R. M., Marchettini, N., and Tiezzi, E. (2008) "Dissipative structures in nature and human systems," in Design \& Nature IV: Comparing Design in Nature with Science and Engineering. WIT Transactions on Ecology and the Environment 114, ed C. A. Brebbia (WIT Press), 293-299.

UNEP (2019). Cities and Climate Change. Available online at: https://www. unenvironment.org/explore-topics/resource-efficiency/what-we-do/cities/ cities-and-climate-change (accesed December 2019).

UN-Habitat (2016). World Cities Report 2016. Urbanization and Development. Emerging Futures. United Nations Human Settlements Programme (UNHabitat) Nairobi: UN-Habitat.

Wackernagel, M., and Rees, W. E. (1996). Our Ecological Footprint: Reducing Human Impact on the Earth. Gabriola Island: New Society Publishers.

World Bank (2015). World Inclusive Cities Approach Paper. Report No. AUS8539. WB, Washington DC: World Bank.

Conflict of Interest: The author declares that the research was conducted in the absence of any commercial or financial relationships that could be construed as a potential conflict of interest.

Copyright (C) 2020 Gallopin. This is an open-access article distributed under the terms of the Creative Commons Attribution License (CC BY). The use, distribution or reproduction in other forums is permitted, provided the original author(s) and the copyright owner(s) are credited and that the original publication in this journal is cited, in accordance with accepted academic practice. No use, distribution or reproduction is permitted which does not comply with these terms. 